Review Article

\title{
Histoplasmosis-Associated Hemophagocytic Lymphohistiocytosis: A Review of the Literature
}

\author{
Ra'ed Jabr, ${ }^{1}$ Wissam El Atrouni, ${ }^{2}$ Heather J. Male, ${ }^{3}$ and Kassem A. Hammoud $\mathbb{D}^{2}$ \\ ${ }^{1}$ Department of Internal Medicine, The University of Kansas Medical Center, Kansas City, KS 66160, USA \\ ${ }^{2}$ Division of Infectious Diseases, The University of Kansas Medical Center, Kansas City, KS 66160, USA \\ ${ }^{3}$ Division of Hematological Malignancies and Cellular Therapeutics, The University of Kansas Medical Center, Kansas City, \\ KS 66160, USA
}

Correspondence should be addressed to Kassem A. Hammoud; khammoud@kumc.edu

Received 20 June 2019; Accepted 30 August 2019; Published 1 October 2019

Academic Editor: Sandra Gemma

Copyright (c) 2019 Ra'ed Jabr et al. This is an open access article distributed under the Creative Commons Attribution License, which permits unrestricted use, distribution, and reproduction in any medium, provided the original work is properly cited.

\begin{abstract}
Background. Histoplasmosis is an endemic fungal disease with diverse clinical presentations. Histoplasmosis-associated hemophagocytic lymphohistiocytosis (HLH) is a rare disorder with limited data regarding treatment and outcome. We described the clinical features, treatment, and outcomes of five patients in our institution with histoplasmosis-associated HLH. This review also summarizes the current literature about presentation, treatment, and outcome of this infection-related HLH entity. Methods. We searched the electronic medical records for patients with histoplasmosis-associated HLH at our institution from 1/1/2006 to 9/30/2017. Diagnosis of HLH was confirmed by chart review using the HLH-04 criteria. We also searched the current literature for case reports and case series. Results. Five cases of histoplasmosis-associated HLH were included from our institution. All five patients were diagnosed after 2010. The literature review yielded 60 additional cases of histoplasmosisassociated HLH. The most common underlying condition was HIV in $61 \%$ of cases. The majority of histoplasmosis patients (81\%) were treated with amphotericin B formulations. Documented specific treatments for HLH were as follows: nine patients received steroids only, six patients received intravenous immunoglobulin (IVIG) only, three patients received dexamethasone and etoposide, two patients received etoposide, dexamethasone, and cyclosporine, two patients received steroids and IVIG, and one patient received Anakinra and IVIG. The inpatient case fatality rate was $31 \%$ with most of the deaths occurring within two weeks of hospital admission. Conclusions. Histoplasmosis-associated HLH among adults is an uncommon but serious complication with high associated mortality. Early antifungal therapy with a lipid formulation amphotericin B is critical. The initiation of immunosuppressive therapy with regimens like HLH-04 in this disease entity should be individualized.
\end{abstract}

\section{Introduction}

Hemophagocytic lymphohistiocytosis (HLH) is a rare but often life-threatening syndrome of excessive immune activation. Primary HLH is triggered by genetic disorders and usually manifests in children below the age of 18 months. The term secondary (acquired) HLH has generally been used to describe cases in adults without known genetic predisposition and a clear trigger for HLH. This trigger is often an infection or an alteration in immune homeostasis (e.g., malignancy, rheumatologic conditions, or immunodeficiency syndromes) [1]. HLH may present as a single episode of disease or recurrent episodes. Histoplasmosis-associated
HLH is a relatively rare disorder with limited data about treatment $[2,3]$. We describe the clinical features, treatment, and outcomes of cases seen at the University of Kansas Medical Center (KUMC). In addition, we reviewed the current literature about diagnosis and treatment of histoplasmosis-associated HLH.

\section{Methods}

We searched our medical informatics HERON (Healthcare Enterprise Repository for Ontological Narration) database for the following ICD9/ICD10 terms: "hemophagocytic syndrome," "hemophagocytosis," "hemophagocytic lymphohistiocytosis" or 
TABLE 1: Clinical characteristics of histoplasmosis-induced HLH patients at our institution $(n=5)$.

\begin{tabular}{|c|c|c|c|c|c|c|c|c|c|c|}
\hline $\begin{array}{l}\text { Case } \\
\#\end{array}$ & Year & Age & Gender & Race & $\begin{array}{l}\text { Comorbid } \\
\text { conditions }\end{array}$ & $\begin{array}{c}\text { Immunosuppressive } \\
\text { agent }\end{array}$ & $\begin{array}{c}\text { Yeast } \\
\text { in BM }\end{array}$ & $\begin{array}{c}\text { Urine } \\
\text { histoplasma Ag }\end{array}$ & $\begin{array}{c}\text { Sites growing } \\
\text { histoplasma }\end{array}$ & CXR findings \\
\hline 1 & 2011 & 48 & M & White & $\begin{array}{l}\mathrm{HIV} / \mathrm{CD} 4 \\
\text { count } 50\end{array}$ & None & Yes & Above LoQ & Blood & No infiltrates \\
\hline 2 & 2014 & 48 & $\mathrm{~F}$ & White & MCTD & $\begin{array}{c}\mathrm{HCQ} / \text { prednisone } \\
10 \mathrm{mg} \text { daily }\end{array}$ & No & Above LoQ & Blood & $\begin{array}{l}\text { LAD without } \\
\text { infiltrates }\end{array}$ \\
\hline 3 & 2016 & 75 & M & White & Crohn's & $\begin{array}{c}\text { Infliximab/ } \\
\text { azathioprine/ } \\
\text { prednisone }\end{array}$ & Yes & $\begin{array}{l}\text { N/A (serum Ag: } \\
\text { above LoQ) }\end{array}$ & Blood and BM & No infiltrates \\
\hline 4 & 2017 & 46 & M & $\begin{array}{l}\text { African } \\
\text { American }\end{array}$ & Sarcoid & Prednisone & Yes & Above LoQ & Blood and BM & $\begin{array}{l}\text { Diffuse } \\
\text { infiltrate }\end{array}$ \\
\hline 5 & 2017 & 41 & M & White & $\begin{array}{l}\mathrm{HIV} / \mathrm{CD} 4 \\
\text { count } 10\end{array}$ & None & N/A & Above LoQ & Blood & $\begin{array}{l}\text { Diffuse } \\
\text { infiltrate }\end{array}$ \\
\hline
\end{tabular}

M: male; F: female; HIV: human immunodeficiency virus; MCTD: mixed connective tissue disease; N/A: not applicable, BM: bone marrow; dexa: dexamethasone; CXR: chest X-ray; Ag: antigen; LAD: lymphadenopathy; LoQ: limit of quantification; HCQ: hydroxychloroquine.

"macrophage activation syndrome" and "histoplasmosis" or "disseminated histoplasmosis." We included patients older than 18 years and seen at our institution from 1/1/2006 to 9/30/2017. All patients who satisfied the HLH-04 criteria [4] for a diagnosis of HLH (i.e., 5 of 8 criteria) and confirmed to have histoplasmosis by retrospective chart review were included. HLH-04 criteria include (1) fever; (2) splenomegaly; (3) cytopenia in two or more cell lines; (4) hypertriglyceridemia (triglyceride level $\geq 265 \mathrm{mg} / \mathrm{dL}$ or hypofibrinogenemia (fibrinogen level $\leq 150 \mathrm{mg}$ / $\mathrm{dL}$ ); [5] hemophagocytosis in the bone marrow, spleen, or lymph nodes; [6] hyperferritinemia (ferritin level $\geq 500 \mathrm{ng} / \mathrm{mL}$ ); [7] impaired NK cell function; and [8] elevated soluble CD25 (soluble IL-2 receptor alpha) two standard deviations above ageadjusted laboratory-specific norms. This study was approved by the University of Kansas Medical Center institutional board review.

\section{Literature Review}

We searched PubMed for "histoplasmosis" and "hemophagocytic syndrome," "histoplasmosis" and "secondary hemophagocytic syndrome," "histoplasmosis induced hemophagocytic syndrome," "disseminated histoplasmosis" and "hemophagocytic syndrome," "HLH" and "histoplasmosis," and "histoplasma associated HLH." Few papers were only available by a Google search. We included all case reports/series with a published abstract in English.

\section{Results}

We identified five cases of histoplasmosis-associated HLH. The clinical characteristics are summarized in Table 1. All patients had disseminated histoplasmosis and were immunosuppressed. Human immunodeficiency virus (HIV) infection was the underlying condition in $2 / 5$ patients $(40 \%)$; the diagnosis of HIV in both patients was new. The other three patients were on steroids in addition to other immunosuppressive agents. There was a male predominance $4 / 5$ (80\%). All patients $5 / 5(100 \%)$ had positive blood cultures for histoplasma, and the histoplasma antigen (blood or urine) was above the limit of quantification. Histoplasma was seen on bone marrow (BM) biopsy in 3/4 (75\%) patients.
Four patients (80\%) met at least 5 out of 8 criteria for the diagnosis of HLH as shown in Table 2. The IL2-receptor, cytopenia, and ferritin criteria were met in all five patients. Peak ferritin level was above the limit of quantification in 4/5 (80\%) patients. One patient met only four criteria, but the hematology consulting team felt that it was highly likely secondary HLH.

The treatment and outcomes are shown in Table 3. Most patients were started on liposomal amphotericin B for at least 2 weeks and then transitioned to an oral azole. One patient received only voriconazole. Three out of five patients survived to hospital discharge.

The literature review yielded 60 cases from 39 papers; most of them were case reports and few were case series. Table 4 summarizes the patients baseline characteristics, treatment used, diagnostic tests for histoplasmosis, and outcomes. Five papers were published before 2000, and 18 papers were published since 2015 . We report five patients at our institution from 1/1/2006 to 9/30/2017 (Table 1). All 5 cases at KUMC were diagnosed after 2010. Adding our five cases to the 60 reported previously, the median age of cases was 41 years and $72 \%(37 / 52)$ were men. The most common underlying immunosuppressive condition was HIV in $62 \%$ (36/58). Six patients had solid organ transplant, and there was no clear underlying immunodeficiency described in seven patients. In eleven patients, there was no mention of the host immune status.

The median CD4 count in HIV patients was 17 cells $/ \mu \mathrm{L}$. The majority of patients had disseminated histoplasmosis. Five patients were diagnosed by either lymph node biopsy or histoplasma urine Ag only and not proven to have disseminated histoplasmosis.

Initial antifungal treatment consisted of amphotericin B formulation in 48 cases and only azoles in four cases. The specific treatment for HLH was as follows: nine patients received steroids only, six patients received intravenous immunoglobulin (IVIG) only, three patients received dexamethasone and etoposide, two patients received etoposide, dexamethasone, and cyclosporine, two patients received steroids and IVIG, and one patient received Anakinra and IVIG.

The overall inpatient case fatality rate was $31 \%(20 / 64)$ and $37 \%(13 / 35)$ among HIV patients. The mortality rate 
TABLE 2: Diagnosis of HLH $(n=5)$.

\begin{tabular}{|c|c|c|c|c|c|c|c|c|}
\hline $\begin{array}{l}\text { Case } \\
\#\end{array}$ & Fever & $\begin{array}{c}\text { Cytopenia } \\
(2 \text { lines })\end{array}$ & $\begin{array}{l}\text { IL2-receptor } \\
(\mathrm{pg} / \mathrm{mL})\end{array}$ & $\begin{array}{c}\text { Peak triglycerides } \\
(\mathrm{mg} / \mathrm{dL})\end{array}$ & $\begin{array}{c}\text { BM with } \\
\text { hemophagocytosis }\end{array}$ & Splenomegaly & $\begin{array}{l}\text { Peak ferritin } \\
(\mathrm{ng} / \mathrm{mL})\end{array}$ & $\begin{array}{c}\text { Nadir fibrinogen } \\
(\mathrm{mg} / \mathrm{dL})\end{array}$ \\
\hline 1 & Yes & Yes & 5167 & 258 & Yes & No & $>15,000$ & 95 \\
\hline 2 & Yes & Yes & 115,900 & 329 & Yes & Yes & 4487 & 265 \\
\hline 3 & No & Yes & 958 & 227 & Yes & No & $>7500$ & 384 \\
\hline 4 & Yes & Yes & 1648 & 192 & No & Yes & $>7500$ & 168 \\
\hline 5 & No & Yes & 15,540 & 246 & N/A & Yes & $>7500$ & 51 \\
\hline
\end{tabular}

TABle 3: Treatment and outcome of histoplasmosis-associated HLH patients at our institution $(n=5)$.

\begin{tabular}{|c|c|c|c|}
\hline Case \# & Antifungal drug & HLH specific treatment & Outcome (hospital discharge) \\
\hline 1 & $\begin{array}{l}\text { Liposomal amphotericin B for } 2 \text { weeks, then } \\
\text { itraconazole for } 12 \text { months }\end{array}$ & None & Survived \\
\hline 2 & $\begin{array}{c}\text { Liposomal amphotericin B for } 4 \text { weeks, then oral } \\
\text { azoles for } 4 \text { years }\end{array}$ & Dexamethasone $10 \mathrm{mg} / \mathrm{m}^{2}$ for 2 days & Survived \\
\hline 3 & $\begin{array}{c}\text { Voriconazole PO (discharged to hospice, patient } \\
\text { preference) }\end{array}$ & None & Discharged to hospice \\
\hline 4 & $\begin{array}{c}\text { Liposomal amphotericin B for } 2 \text { weeks then } \\
\text { itraconazole for } 4 \text { months }\end{array}$ & Dexamethasone $10 \mathrm{mg} / \mathrm{m}^{2}$ & Survived \\
\hline 5 & $\begin{array}{l}\text { Liposomal amphotericin B for } 2 \text { weeks then oral } \\
\text { azoles }\end{array}$ & None & Died (day 43) \\
\hline
\end{tabular}

Notes. BM: bone marrow, IL: interleukin, N/A: not applicable.

was $25.0 \%(12 / 48)$ in patients who received amphotericin $B$, $20 \%(1 / 5)$ in patients who received steroids and etoposide with or without cyclosporine (all received amphotericin B), $62 \%(5 / 8)$ in patients who received IVIG, and $31 \%(5 / 16)$ in patients who received steroids. One patient received Anakinra and IVIG and survived. Only 14/21 patients had available date of death; of those, 10 patients died within two weeks of admission and four patients died at hospital days $16,18,43$, and 44 .

\section{Discussion}

Histoplasmosis-associated HLH is rare but likely underdiagnosed given the nonspecific clinical and laboratory presentation. The diagnosis is challenging because high fever, peripheral blood cytopenia, splenomegaly, and elevated ferritin are very common in patients with disseminated histoplasmosis. We report the second largest case series of histoplasmosis-induced HLH. About half of the cases (29/60) were reported after 2014, and all five cases at our institution were diagnosed after 2010. This may be explained by an increased awareness of this entity. Almost all cases of histoplasmosis-associated HLH occurred in patients with disseminated histoplasmosis. Most patients were relatively young. HIV and its numerous related opportunistic infections remain the most common underlying immunodeficiency that triggers HLH, but the recent literature showed an increasing number of non-HIV patients (organ transplant, patients receiving chemotherapy, or other immunosuppressive treatments). This is likely caused by the recent increase in disseminated histoplasmosis among non-HIV infected patients $[43,44]$. Only few patients had no clear underlying immunodeficiency. The male predominance may be related in part to the higher incidence and prevalence of HIV in men in the United States.
Human immunodeficiency virus (HIV) could trigger hemophagocytic syndrome by itself, or secondary to ART initiation or opportunistic infections [45]. In a retrospective study to evaluate the triggers of HLH among HIV patients in Brazil, opportunistic infections were the most common factors (59\%) including Mycobacterium (34\%), Cytomegalovirus (14\%), and Cryptococcus neoformans (11\%) [46].

Macrophage activation syndrome (MAS) is a form of HLH that is usually associated with rheumatologic diseases and inflammatory bowel diseases (IBD). In a review of literature of 50 cases of HLH or MAS, the association between HLH and IBD was thought to be secondary to infections, the effect of immunosuppressive therapy, and the potential presence of a genetic susceptibility [47]. The majority of cases were Crohn's disease (CD) rather than ulcerative colitis; this was attributed to the more frequent use of immunomodulators in CD.

The number of patients in each treatment group and the noncontrolled nature of this review hinder making conclusions about the most effective therapy. Patients who received amphotericin $B$ had a slightly lower case fatality rate compared to the whole group. It is unclear if the addition of etoposide and steroids was helpful, but 4/5 patients with such regimen survived. We suggest starting a lipid formulation of amphotericin B as soon as possible, as recommended by the Infectious Diseases Society of America guidelines [48] for the treatment of moderate to severe disseminated histoplasmosis. There are limited data to establish the best treatment protocol and the role of immunosuppressive therapy and IVIG for histoplasma-associated HLH [1].

The treatment of secondary HLH is most effective when the inciting disease can be treated and controlled. If effective histoplasmosis treatment fails to demonstrate improvement after 48-72 hours, clinicians often consider initiation of 


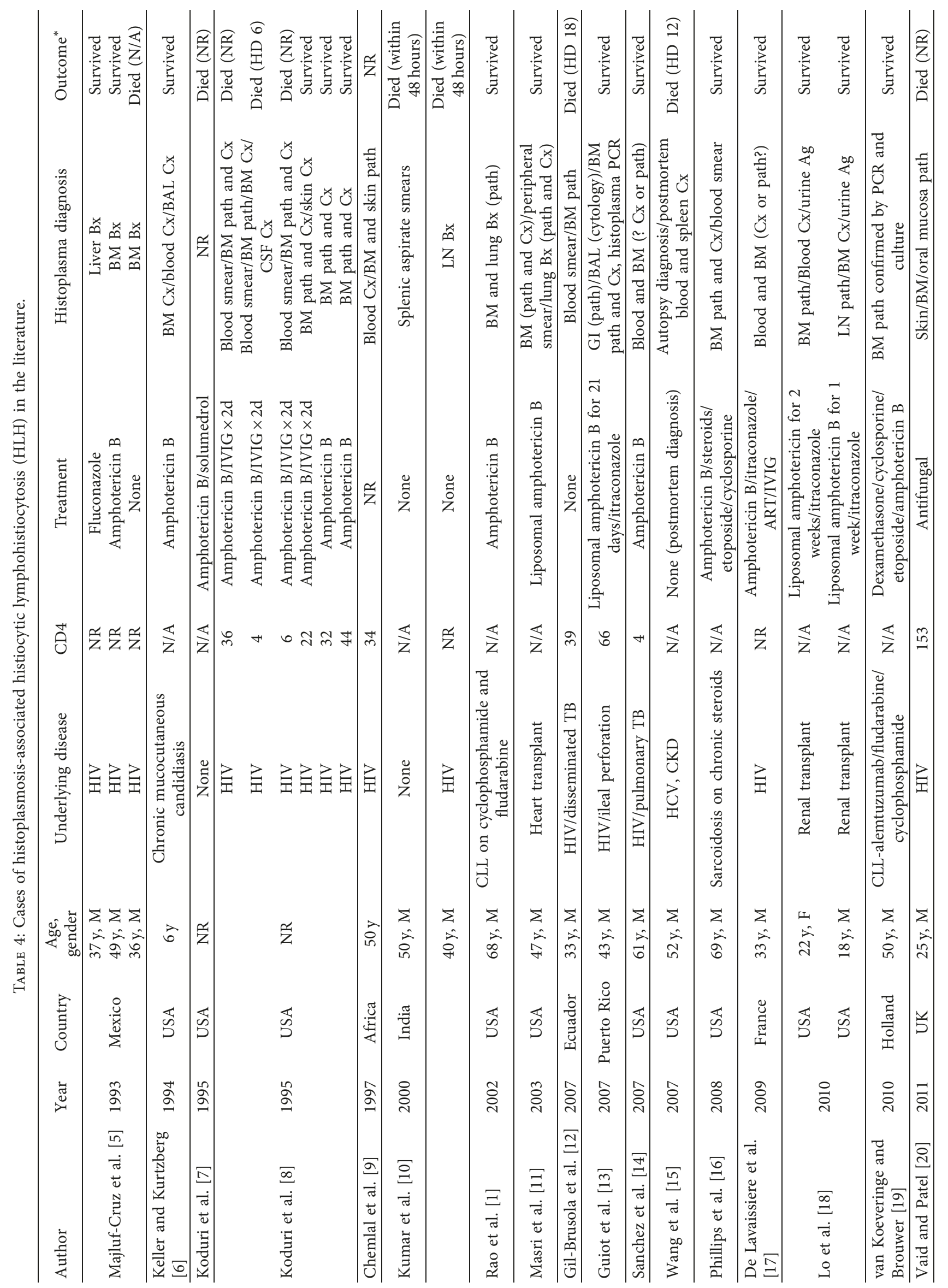




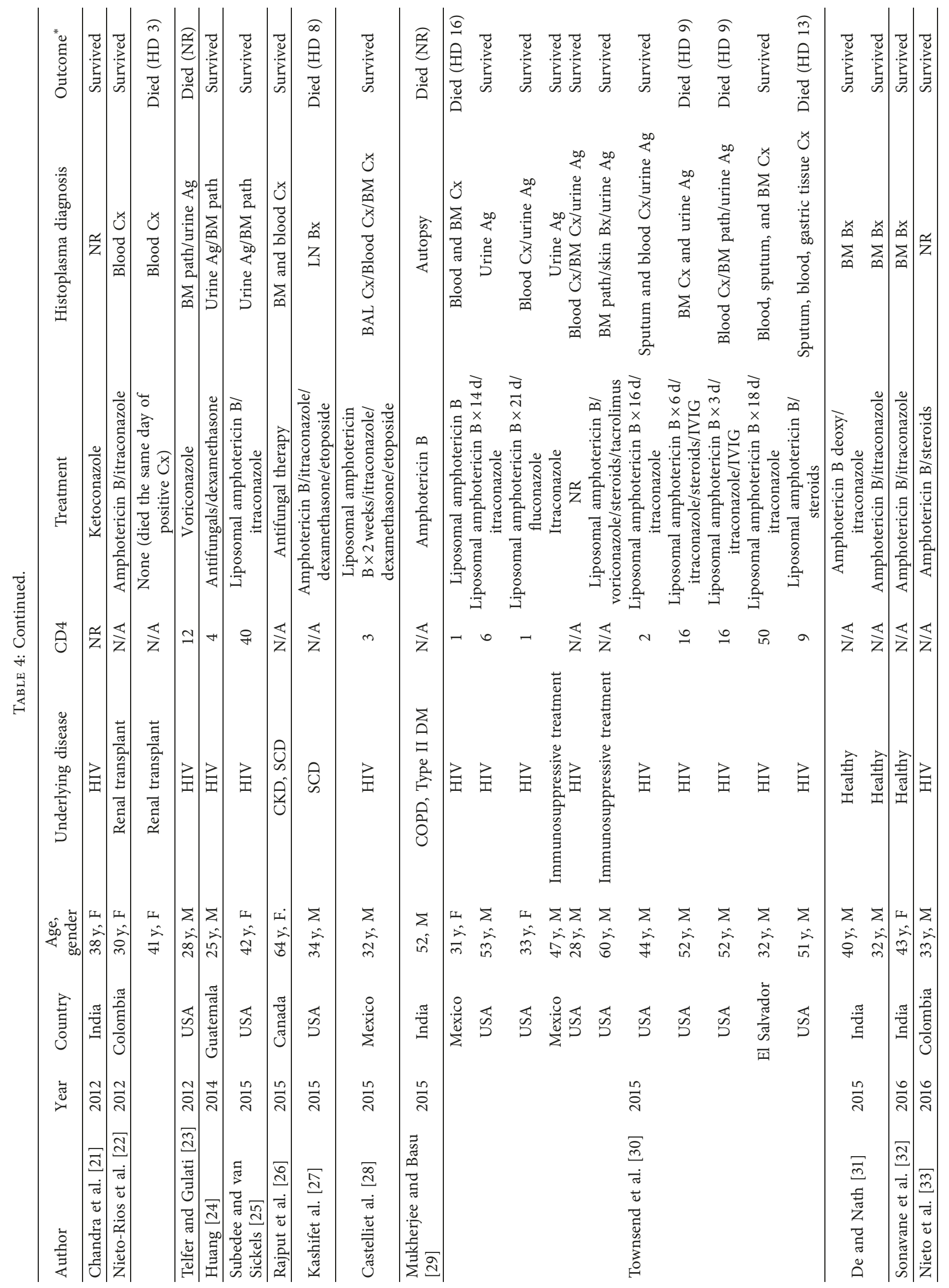




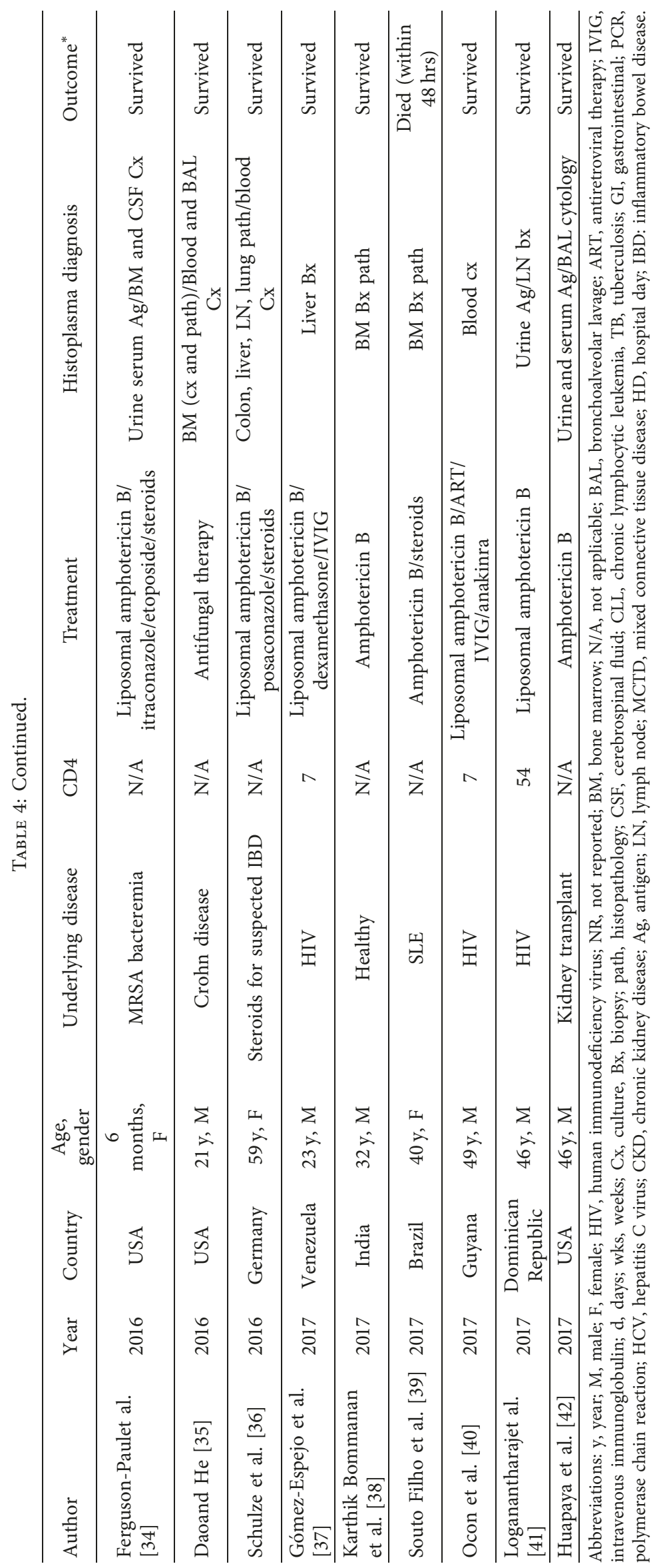


immunosuppressive therapy with regimens such as the HLH-94 protocol [49]. Once clinical improvement is noted, we believe immunosuppressive therapy can be tapered, and the full protocol is often not required.

We report a small number of cases at our institution and it is possible that we could have missed cases in our retrospective search. In published case reports and case series, some data were lacking and few articles were not in English.

\section{Conclusions}

Histoplasmosis-associated HLH among adults is an uncommon but serious disease with high mortality. The clinical and laboratory findings that should prompt evaluation for HLH are splenomegaly, highly elevated ferritin, and cytopenia in an immunocompromised patient with disseminated histoplasmosis. The delay in diagnosis of HLH may affect outcomes and patients with suspected HLH should have a prompt hematology consultation. HLH appears to be a disease of excessive immune activation, and the optimal treatment and duration of immunosuppressive therapy remains unknown. Early antifungal therapy with a lipid formulation amphotericin B is critical. Multicenter prospective studies are needed to help define the role and duration of immunosuppressive therapy for this disease.

\section{Conflicts of Interest}

The authors declare that they have no conflicts of interest.

\section{References}

[1] R. D. Rao, W. G. Morice, and R. L. Phyliky, "Hemophagocytosis in a patient with chronic lymphocytic leukemia and histoplasmosis," Mayo Clinic proceedings, vol. 77, no. 3, pp. 287-290, 2002.

[2] N. G. Rouphael, N. J. Talati, C. Vaughan, K. Cunningham, R. Moreira, and C. Gould, "Infections associated with haemophagocytic syndrome," The Lancet Infectious Diseases, vol. 7, no. 12, pp. 814-822, 2007.

[3] A. H. Filipovich, "The expanding spectrum of hemophagocytic lymphohistiocytosis," Current Opinion in Allergy and Clinical Immunology, vol. 11, no. 6, pp. 512-516, 2011.

[4] M. B. Jordan, C. E. Allen, S. Weitzman, A. H. Filipovich, and K. L. McClain, "How I treat hemophagocytic lymphohistiocytosis," Blood, vol. 118, no. 15, pp. 4041-4052, 2011.

[5] A. S. Majluf-Cruz, R. Hurtado Monroy, C. Souto-Meirino, C. del Rio Chiriboga, and J. Simon, "Hemophagocytic syndrome associated with histoplasmosis in the acquired immunodeficiency syndrome: description of 3 cases and review of the literature," Sangre, vol. 38, no. 1, pp. 51-55, 1993.

[6] F. G. Keller and J. Kurtzberg, "Disseminated histoplasmosis: a cause of infection-associated hemophagocytic syndrome," The American Journal of Pediatric Hematology/Oncology, vol. 16, no. 4, pp. $368-371,1994$.

[7] P. R. Koduri, G. Carandang, P. DeMarais, and A. R. Patel, "Hyperferritinemia in reactive hemophagocytic syndrome report of four adult cases," American Journal of Hematology, vol. 49, no. 3, pp. 247-249, 1995.

[8] P. R. Koduri, V. Chundi, P. DeMarais, B. A. Mizock, A. R. Patel, and R. A. Weinstein, "Reactive hemophagocytic syndrome: a new presentation of disseminated histoplasmosis in patients with AIDS," Clinical Infectious Diseases, vol. 21, no. 6, pp. 1463-1465, 1995.

[9] K. Chemlal, V. Andrieu-Bautru, and A. Couvelard, "Hemophagocytic syndrome during histoplasma capsulatum infection," Haematologica, vol. 82, no. 6, p. 726, 1997.

[10] N. Kumar, S. Jain, and Z. N. Singh, "Disseminated histoplasmosis with reactive hemophagocytosis: aspiration cytology findings in two cases," Diagnostic Cytopathology, vol. 23, no. 6, pp. 422-424, 2000.

[11] K. Masri, N. Mahon, A. Rosario et al., "Reactive hemophagocytic syndrome associated with disseminated histoplasmosis in a heart transplant recipient," The Journal of Heart and Lung Transplantation, vol. 22, no. 4, pp. 487-491, 2003.

[12] A. Gil-Brusola, J. Pemán, M. Santos, M. Salavert, J. Lacruz, and M. Gobernado, "Histoplasmosis diseminada con síndrome hemofagocítico en un paciente con sida: descripción de un caso y revisión de la literatura española," Revista Iberoamericana de Micología, vol. 24, no. 4, pp. 312316, 2007.

[13] H. M. Guiot, J. Bertrán-Pasarell, L. M. Tormos et al., "Ileal perforation and reactive hemophagocytic syndrome in a patient with disseminated histoplasmosis: the role of the real-time polymerase chain reaction in the diagnosis and successful treatment with amphotericin B lipid complex," Diagnostic Microbiology and Infectious Disease, vol. 57, no. 4, pp. 429-433, 2007.

[14] A. Sanchez, A. K. Celaya, and A. Victorio, "Histoplasmosisassociated hemophagocytic syndrome: a case report," AIDS Read, vol. 17, no. 10, pp. 496-499, 2007.

[15] Z. Wang, A. G. Duarte, and V. J. Schnadig, "Fatal reactive hemophagocytosis related to disseminated histoplasmosis with endocarditis: an unusual case diagnosed at autopsy," Southern Medical Journal, vol. 100, no. 2, pp. 208-211, 2007.

[16] J. Phillips, H. Staszewski, and M. Garrison, "Successful treatment of secondary hemophagocytic lymphohistiocytosis in a patient with disseminated histoplasmosis," Hematology, vol. 13 , no. 5 , pp. $282-285,2008$.

[17] M. De Lavaissière, V. Manceron, P. Bourée et al., "Reconstitution inflammatory syndrome related to histoplasmosis, with a hemophagocytic syndrome in HIV infection," Journal of Infection, vol. 58, no. 3, pp. 245-247, 2009.

[18] M. M. Lo, J. Q. Mo, B. P. Dixon, and K. A. Czech, "Disseminated histoplasmosis associated with hemophagocytic lymphohistiocytosis in kidney transplant recipients," American Journal of Transplantation, vol. 10, no. 3, pp. 687-691, 2010.

[19] M. P. van Koeveringe and R. E. Brouwer, "Histoplasma capsulatum reactivation with haemophagocytic syndrome in a patient with chronic lymphocytic leukaemia," The Netherlands Journal of Medicine, vol. 68, no. 12, pp. 418-421, 2010.

[20] N. Vaid and P. Patel, "A case of haemophagocytic syndrome in HIV-associated disseminated histoplasmosis," Acute Medicine, vol. 10, no. 3, pp. 142-144, 2011.

[21] H. Chandra, S. Chandra, and A. Sharma, "Histoplasmosis on bone marrow aspirate cytological examination associated with hemophagocytosis and pancytopenia in an AIDS patient," The Korean Journal of Hematology, vol. 47, no. 1, pp. 77-79, 2012.

[22] J. F. Nieto-Rios, A. Aristizabal-Alzate, C. Ocampo, A. K. Serrano-Gayubo, L. M. Serna-Higuita, and G. ZuluagaValencia, "Disseminated histoplasmosis and haemophagocytic syndrome in two kidney transplant patients," Nefrologia: publicacion oficial de la Sociedad Espanola Nefrologia, vol. 32, no. 5, pp. 683-684, 2012. 
[23] M. Telfer and S. Gulati, "Hemophagocytic lymphohistiocytosis in a patient with disseminated histoplasmosis: a case report," Journal of Hospital Medicine, vol. 7, no. suppl 2, article 978433, Article ID 978433, 2012.

[24] A. M. Huang, "Hemophagocytic lymphohistiocytosis and disseminated histoplasmosis," Blood, vol. 123, no. 16, p. 2449, 2014.

[25] A. Subedee and N. van Sickels, "Hemophagocytic syndrome in the setting of AIDS and disseminated histoplasmosis," Journal of the International Association of Providers of AIDS Care (JIAPAC), vol. 14, no. 5, pp. 391-397, 2015.

[26] A. Rajput, I. Bence-Bruckler, L. Huebsch, P. Jessamine, B. Toye, and R. Padmore, "Disseminated histoplasmosis associated with acquired hemophagocytic lymphohistiocytosis," Clinical Case Reports, vol. 3, no. 3, pp. 195-196, 2015.

[27] M. Kashif, H. Tariq, M. Ijaz, and J. Gomez-Marquez, "Disseminated histoplasmosis and secondary hemophagocytic syndrome in a non-HIV patient," Case Reports in Critical Care, vol. 2015, Article ID 295735, 5 pages, 2015.

[28] A. A. Castelli, D. G. Rosenthal, R. Bender Ignacio, and H. Y. Chu, "Hemophagocytic lymphohistiocytosis secondary to human immunodeficiency virus-associated histoplasmosis," Open Forum Infectious Diseases, vol. 2, no. 4, Article ID ofv140, 2015.

[29] T. Mukherjee and A. Basu, "Disseminated histoplasmosis presenting as a case of erythema nodosum and hemophagocytic lymphohistiocytosis," Medical Journal Armed Forces India, vol. 71, no. 2, pp. S598-S600, 2015.

[30] J. L. Townsend, S. Shanbhag, J. Hancock, K. Bowman, and A. E. Nijhawan, "Histoplasmosis-induced hemophagocytic syndrome: a case series and review of the literature," Open Forum Infectious Diseases, vol. 2, no. 2, Article ID ofv055, 2015.

[31] D. De and U. K. Nath, "Disseminated histoplasmosis in immunocompetent individuals- not a so rare entity," Mediterranean Journal of Hematology and Infectious Diseases, vol. 7, no. 1, Article ID e2015028, 2015.

[32] A. D. Sonavane, P. B. Sonawane, S. V. Chandak, and P. M. Rathi, "Disseminated histoplasmosis with haemophagocytic lymphohistiocytosis in an immunocompetent host," Journal of Clinical and Diagnostic Research, vol. 10, no. 3, pp. Od03-OD05, 2016.

[33] J. F. Nieto, S. M. Gómez, D. C. Moncada, L. M. Serna, and A. I. Hidrón, "Tratamiento exitoso de linfohistiocitosis hemofagocítica y coagulación intravascular diseminada secundarios a histoplasmosis en un paciente con VIH/sida," Biomédica, vol. 36, no. 0, pp. 9-14, 2016.

[34] K. Ferguson-Paul, S. Mangum, A. Porter, V. Leventaki, P. Campbell, and J. Wolf, "Hemophagocytic lymphohistiocytosis and progressive disseminated histoplasmosis," Emerging Infectious Diseases, vol. 22, no. 6, pp. 1119-1121, 2016.

[35] L. N. Dao and R. He, "Hemophagocytic lymphohistiocytosis secondary to iatrogenic disseminated histoplasmosis," Blood, vol. 127, no. 22, p. 2775, 2016.

[36] A. B. Schulze, B. Heptner, T. Kessler et al., "Progressive histoplasmosis with hemophagocytic lymphohistiocytosis and epithelioid cell granulomatosis: a case report and review of the literature," European Journal of Haematology, vol. 99, no. 1, pp. 91-100, 2017.

[37] S. M. Gómez-Espejo, J. Olalla-Sierra, P. Marí-Jiménez et al., "Reconstitution inflammatory syndrome like reactive hemophagocytic syndrome associated with disseminated histoplasmosis in a HIV patient," Mycopathologia, vol. 182, no. 7-8, pp. 767-770, 2017.

[38] B. Karthik Bommanan, S. Naseem, and N. Varma, "Hemophagocytic lymphohistiocytosis secondary to histoplasmosis," Blood Research, vol. 52, no. 2, p. 83, 2017.

[39] J. T. D. Souto Filho, P. D. A. Lima, A. B. Paulo, and A. L. S. Souza, "Hemophagocytic lymphohistiocytosis secondary to disseminated histoplasmosis in systemic lupus erythematosus," International Journal of Hematology, vol. 106, no. 6, pp. 727-728, 2017.

[40] A. J. Ocon, B. D. Bhatt, C. Miller, and R. A. Peredo, "Safe usage of anakinra and dexamethasone to treat refractory hemophagocytic lymphohistiocytosis secondary to acute disseminated histoplasmosis in a patient with HIV/AIDS," BMJ Case Reports, vol. 2017, pp. bcr-2017, 2017.

[41] N. Loganantharaj, B. Oliver, T. Smith, R. Jetly, L. Engel, and S. Sanne, "Hemophagocytic lymphohistiocytosis in an HIVpositive patient with concomitant disseminated histoplasmosis," International Journal of STD \& AIDS, vol. 29, no. 9, pp. 925-928, 2018.

[42] J. Huapaya, E. Yogiaveetil, and E. Anderson, "Hemophagocytic lymphohistiocytosis induced by histoplasmosis in a kidney transplant patient: are steroids really necessary?," Chest, vol. 152, no. 4, p. A189, 2017.

[43] M. Assi, S. Martin, L. J. Wheat et al., "Histoplasmosis after solid organ transplant," Clinical Infectious Diseases, vol. 57, no. 11, pp. 1542-1549, 2013.

[44] C. A. Hage, J. A. Ribes, N. L. Wengenack et al., "A multicenter evaluation of tests for diagnosis of histoplasmosis," Clinical Infectious Diseases, vol. 53, no. 5, pp. 448-454, 2011.

[45] R. V. Ferraz, A. C. Carvalho, F. Araújo, C. Koch, C. Abreu, and A. Sarmento, "Acute HIV infection presenting as hemophagocytic syndrome with an unusual serological and virological response to ART, "BMC Infectious Diseases, vol. 16, no. 1, p. 619, 2016.

[46] J. P. Telles, M. de Andrade Perez, R. Marcusso, K. Correa, R. F. A. Teixeira, and W. M. Tobias, "Hemophagocytic syndrome in patients living with HIV: a retrospective study," Annals of Hematology, vol. 98, no. 1, pp. 67-72, 2019.

[47] W. Fries, M. Cottone, and A. Cascio, "Systematic review: macrophage activation syndrome in inflammatory bowel disease," Alimentary Pharmacology \& Therapeutics, vol. 37, no. 11, pp. 1033-1045, 2013.

[48] L. J. Wheat, A. G. Freifeld, M. B. Kleiman et al., "Clinical practice guidelines for the management of patients with histoplasmosis: 2007 update by the infectious diseases society of America," Clinical Infectious Diseases, vol. 45, no. 7, pp. 807-825, 2007.

[49] A. M. Schram and N. Berliner, "How i treat hemophagocytic lymphohistiocytosis in the adult patient," Blood, vol. 125, no. 19 , pp. $2908-2914,2015$. 


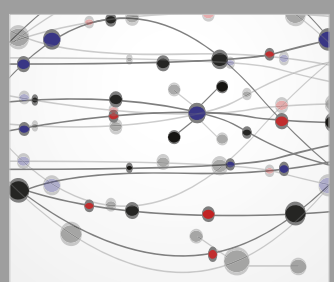

The Scientific World Journal
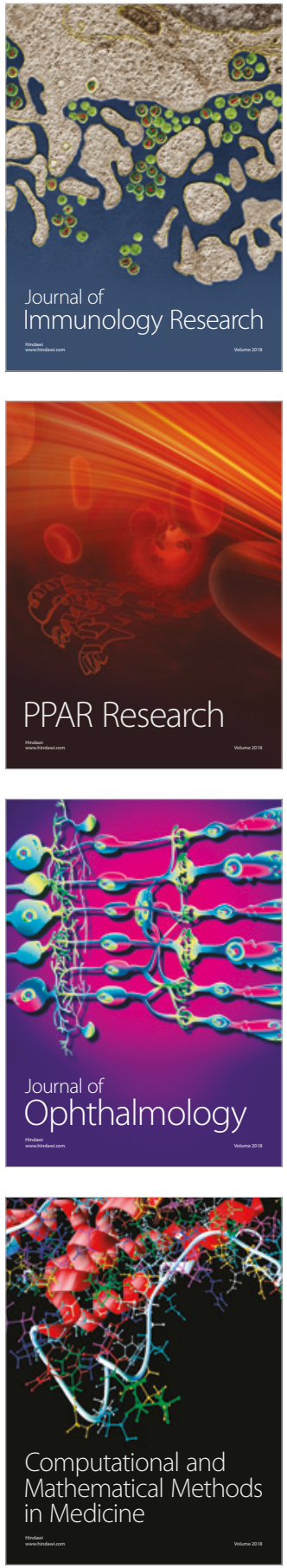

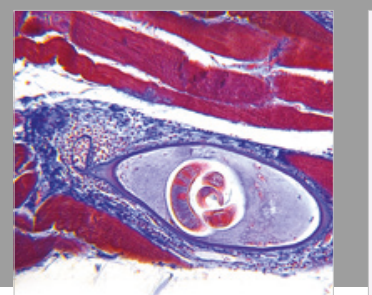

Gastroenterology Research and Practice

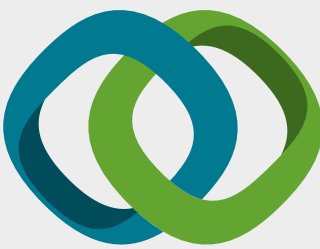

\section{Hindawi}

Submit your manuscripts at

www.hindawi.com
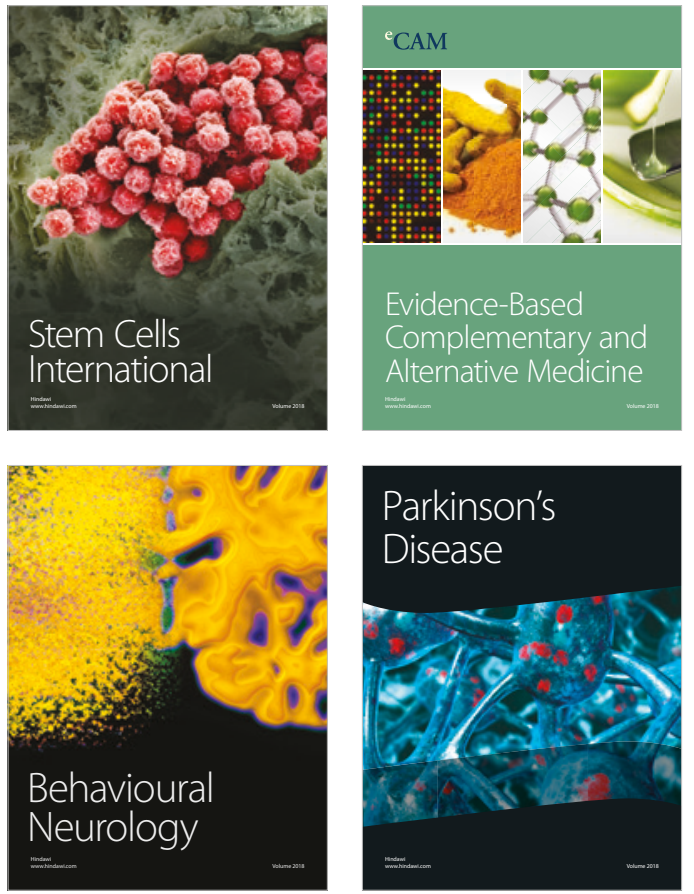

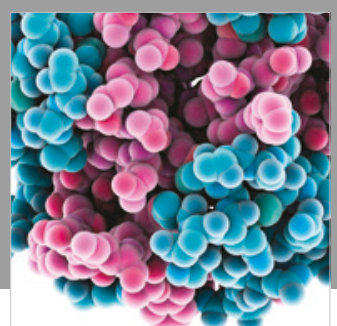

ournal of

Diabetes Research

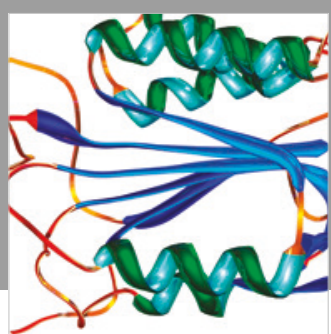

Disease Markers
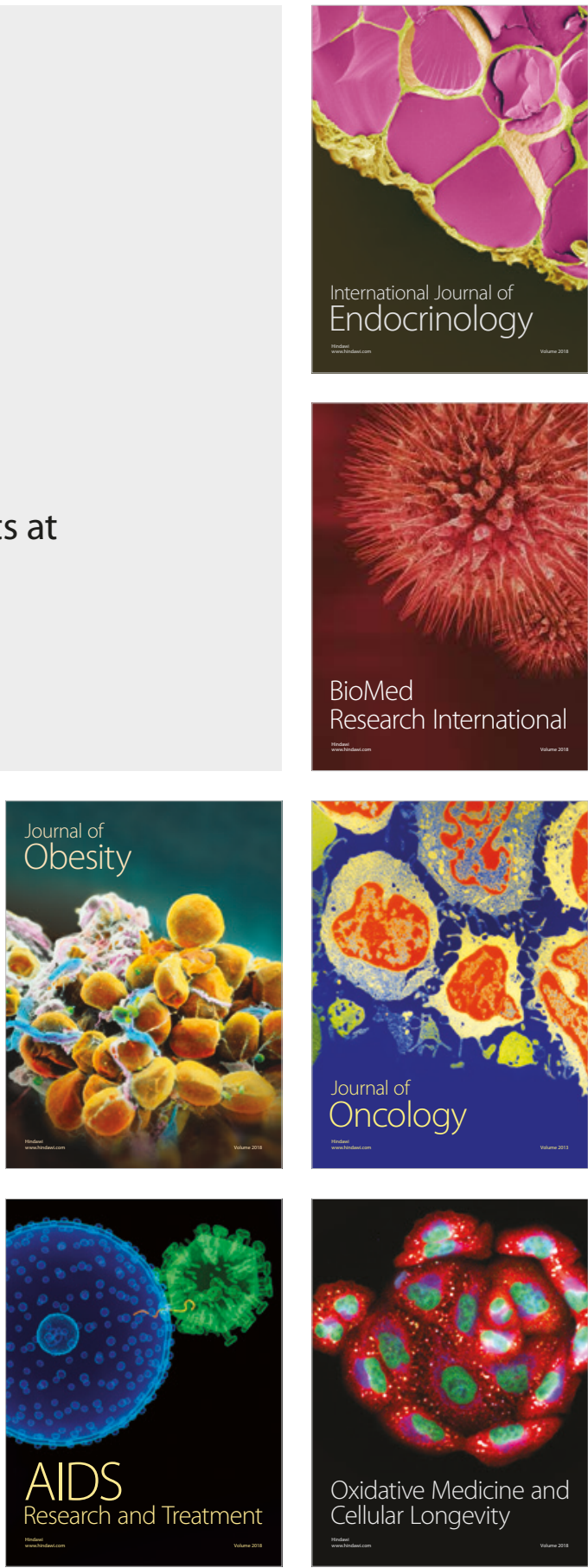